\title{
Inhibitory effect of Salicornia europaea on the marine alga Skeletonema costatum
}

\author{
JIANG Dan ${ }^{1,2}$, HUANG LingFeng ${ }^{3}$, LIN YongQing ${ }^{3}$, NIE LingLing ${ }^{1}$, LV SuLian ${ }^{1}$, \\ KUANG Ting Yun ${ }^{1} \&$ LI YinXin ${ }^{1 *}$ \\ ${ }^{1}$ Key Laboratory of Plant Molecular Physiology, Institute of Botany, Chinese Academy of Sciences, Beijing 100093, China: \\ ${ }^{2}$ Graduate University of Chinese Academy of Sciences, Beijing 100080, China; \\ ${ }^{3}$ College of Oceanography and Environmental Science, Xiamen University, Xiamen 361005, China
}

Received February 21, 2012; accepted April 19, 2012

\begin{abstract}
Exploiting the negative biochemical interference between plants and algal species has been suggested as a method to control harmful algal blooms. In this work, we investigated the inhibitory effect of the salt marsh halophyte Salicornia europaea against the marine alga Skeletonema costatum. S. europaea suppressed the growth of S. costatum in a nutrient-sufficient co-culture system, indicating that the inhibition of algal growth was because of the phytotoxic effect of $S$. europaea, rather than nutrient competition. We tested aqueous and organic extracts from $S$. europaea roots against $S$. costatum. The organic extracts inhibited growth and affected the cell size and chlorophyll $a$ content of $S$. costatum in a dose-dependent manner. Among the three tested organic extracts, the methanol extract had the greatest effects on $S$. costatum, followed by butanol extract, and then the chloroform extract. Two flavonoids, rutin and quercetin-3- $\beta$-D-glucoside, were identified in the methanol extract by high performance liquid chromatography. The concentration of rutin was much higher than that of quercetin-3- $\beta$-D-glucoside. In an algal bioassay, rutin inhibited the growth of $S$. costatum and the inhibitory effect increased with increasing rutin concentration and with decreasing initial algal density. Therefore, we concluded that $S$. europaea negatively affects the growth of $S$. costatum, and that rutin, a metabolite of $S$. europaea, may play a role in this inhibitory effect.
\end{abstract}

dose-dependent, root extracts, rutin, Salicornia europaea, Skeletonema costatum

Citation: Jiang D, Huang L F, Lin Y Q, et al. Inhibitory effect of Salicornia europaea on the marine alga Skeletonema costatum. Sci China Life Sci, 2012, 55: 551-558, doi: 10.1007/s11427-012-4328-5

Harmful algal blooms (HABs) are now widespread and have significant negative effects on human health, fishery resources, and marine ecosystems throughout the world [1]. Therefore, there is a pressing need to develop management and mitigation strategies to respond to HABs. Recent studies have confirmed that bacteria [2], yeast [3], phytoplankton [4], macrophytes [5] and angiosperms [6] can inhibit HABs in freshwater. However, little attention has been paid to the marine ecosystems, such as Yundang Lagoon $\left(24^{\circ} 47^{\prime} 14^{\prime \prime} \mathrm{N}, 118^{\circ} 08^{\prime} 23^{\prime \prime} \mathrm{E}\right)$ in the center of Xiamen City, Southeast China, where high eutrophication has drawn pub-

*Corresponding author (email: yxli@ibcas.ac.cn) lic attention for years. Long-term investigations have shown that Skeletonema costatum, a common nearshore marine diatom, is the predominant bloom-forming species in Yundang Lagoon [7]. S. costatum is a good bio-indicator of eutrophication in coastal marine waters [8].

Salicornia europaea is a salt marsh halophyte belonging to the Chenopodiaceae, and is one of the most salt-tolerant plant species in the world. In previous studies, it was reported that $S$. europaea has potential for use as a phytoremediation plant in saline soil [9] and for life support systems in space stations [10]. Could it play a role in phytoremediation of eutrophic coastal waters such as Yundang Lagoon? During our field study in Yundang Lagoon, we ob- 
served that after one year of $S$. europaea cultivation in a floating phytoremediation platform system, nutrient concentrations and/or populations of marine algae markedly decreased. In particular, the cell density of $S$. costatum decreased by $57 \%$ compared with the same period in the previous year. In light of these findings, we aimed to test the inhibitory effect of $S$. europaea plants and root extracts, including an aqueous extract and three organic extracts, on S. costatum. We analyzed the root extract by high performance liquid chromatography (HPLC) to identify possible active compounds, and then tested the inhibitory activities of isolated compounds against growth of S. costatum.

\section{Materials and methods}

\subsection{Algal and halophyte culture}

Unialgal cultures of the diatom S. costatum (YDL1108) were obtained from the Marine Ecology Laboratory, Xiamen University, China. The alga was routinely maintained in $\mathrm{f} / 2$ medium [11] in an illuminated incubator under the following conditions: temperature, $20^{\circ} \mathrm{C}$; photoperiod, $12 \mathrm{~h}$ light/12 $\mathrm{h}$ dark; photon flux density (PFD), $72 \mu \mathrm{mol} \mathrm{m}{ }^{-2} \mathrm{~s}^{-1}$. The flask was shaken twice a day. The alga was cultured to the exponential phase before inoculation in the following experiments.

S. europaea seeds obtained from Dafeng Jinglong Marine Industrialized Development Corporation, Jiangsu Province, were germinated in vermiculite. Seedlings were hydroponically cultured with filtered seawater $(0.45 \mu \mathrm{m})$ from the Xiamen Western Sea under a 12-h light/12-h dark photoperiod at $22 / 30^{\circ} \mathrm{C}$ with a PFD of $130 \mu \mathrm{mol} \mathrm{m} \mathrm{m}^{-2}$.

\subsection{Preparation of $S$. europaea root extracts}

$S$. europaea plants were collected randomly so that the sample set included natural phenotypic variation. The plants were rinsed carefully with sterile seawater, and then the fresh roots were immediately lyophilized for $48 \mathrm{~h}$ with a vacuum freeze dryer (TFD5505, SIM, USA). The freezedried roots were ground into a fine powder, and then the powder was sieved through nylon mesh $(96 \mu \mathrm{m})$ and ultrasonically extracted in chloroform $(100 \mathrm{~mL}$ per $20 \mathrm{~g}$ dry weight of powder) for $1 \mathrm{~h}$. Then, the mixture was kept in the dark at room temperature for $1 \mathrm{~d}$. Each sample was extracted three times. The total liquid extract was filtered (Whatman $\mathrm{GF} / \mathrm{F}$ ) to remove plant debris, and then vacuum-dried. The remaining powder was extracted successively with butanol, methanol, and distilled water using the same procedure as mentioned above. The prepared extracts were stored at $-20^{\circ} \mathrm{C}$ until use.

\subsection{Algal bioassays with $S$. europaea in a co-culture system}

Each aquarium $(30 \mathrm{~cm} \times 20 \mathrm{~cm} \times 30 \mathrm{~cm})$ was filled with $16 \mathrm{~L}$ $\mathrm{f} / 2$ medium and inoculated with $S$. costatum in the exponential growth phase. The initial algal cell density in the culture medium was $0.5 \times 10^{3}$ cells $\mathrm{mL}^{-1}$. In the co-culture system, $S$. europaea was transplanted into the aquarium with a biomass concentration of $10 \mathrm{~g}$ fresh weight per liter $\left(\mathrm{FW} \mathrm{L}^{-1}\right)$. A monoculture of $S$. costatum without $S$. europaea served as the control. The initial $\mathrm{pH}$ and salinity of the culture medium were adjusted to $8.0 \pm 0.2$ and 30 practical salinity units (psu), respectively. Each experimental treatment was carried out in triplicate. The culture medium was continuously aerated and circulated to prevent formation of gradients. All aquaria were placed in a greenhouse under the following conditions: $22 / 30^{\circ} \mathrm{C}$ during the dark and light periods, $12-\mathrm{h}$ light/12-h dark photoperiod, PFD of $130 \mu \mathrm{mol} \mathrm{m}{ }^{-2} \mathrm{~s}^{-1}$. After treatment for $2 \mathrm{~d}$, extra half strength $\mathrm{f} / 2$ nutrient solution was added to the culture medium of the control and co-culture system. The chlorophyll $a(\mathrm{Chl} a)$ concentration, algal cell density, and the concentrations of dissolved inorganic phosphate (DIP) and dissolved inorganic nitrogen (DIN) in the culture media were determined daily [12]. To determine the rate of cell division, specific growth rates $(\mu)$ [13] of $S$. costatum were calculated as follows:

$$
\mu=\left(\ln N_{t}-\ln N_{0}\right) / t \text {, }
$$

where $N_{t}$ and $N_{0}$ are maximum cell density at time $t$ and 0 , respectively. The specific algal growth rate under each treatment was normalized and the inhibition ratio was determined as follows [14]:

Inhibition ratio $(\%)=\left(1-\mu_{\mathrm{p}} / \mu_{\mathrm{c}}\right) \times 100$,

where $\mu_{\mathrm{p}}$ and $\mu_{\mathrm{c}}$ are the specific growth rates with or without co-cultured $S$. europaea, respectively.

\subsection{Determination of inhibitory effects of $S$. europaea root extracts}

S. costatum was inoculated into a $100-\mathrm{mL}$ flask filled with $40 \mathrm{~mL}$ fresh $\mathrm{f} / 2$ medium to an initial cell density of $2 \times 10^{3}$ cells $\mathrm{mL}^{-1}$. The stock solutions of root extracts were redissolved in the original solvents and then separately added to the $f / 2$ medium. The final concentrations of original solvents were maintained at $0.01 \%(\mathrm{v} / \mathrm{v})$ in all tests. $S$. costatum inoculated into either $\mathrm{f} / 2$ medium or a mixture of solvent and f/ 2 medium served as controls. Each assay consisted of six replicates. The culture conditions were the same as those described above. Algal cell density and Chl $a$ concentration were determined daily as described by Jiang and colleagues [12]. The morphological features of S. costatum cells were observed during the exponential growth phase under a fluorescence microscope (Leica DM4500B, Germany) at 400× magnification. Algal cell length and width were measured with Image Measurement Software (Image-Pro Express 6.0), and algal cell biovolume was calculated as follows [15]:

$$
V=\left(\pi \times(3 \times L-W) \times(W / 2)^{\wedge} 2\right) / 3,
$$

where $V$ is biovolume $\left(\mu \mathrm{m}^{3}\right), L$ is the length $(\mu \mathrm{m})$ and $W$ is the width $(\mu \mathrm{m})$ of algal cells. The effects of root extracts 
were evaluated by determining the half maximal inhibitory concentration $\left(\mathrm{IC}_{50}\right)$. The $\mathrm{IC}_{50}$ data from the control and treatments were subjected separately to four regression analyses, consisting of linear, sigmoid, exponential, and polynomial models. On the basis of statistical criteria, the best-fitting model was chosen for each extract.

\subsection{HPLC analysis}

Analytical HPLC was performed using an Alliance system (Waters, USA), including a W2695 HPLC pump and a W2996 photodiode array detector. The liquid chromatograph was equipped with a Symmetry $C_{18}$ column (250 $\mathrm{mm} \times 4.6 \mathrm{~mm}, 5 \mu \mathrm{m}$; Waters). The following solvents and gradient were used: A, $0.2 \%$ phosphoric acid; B, methanol [16]; linear gradient, 0 min $2 \% \mathrm{~B}, 10 \mathrm{~min} 2 \% \mathrm{~B}, 15 \mathrm{~min}$ $45 \% \mathrm{~B}, 26 \min 45 \% \mathrm{~B}, 27 \min 2 \% \mathrm{~B}, 37 \min 2 \% \mathrm{~B}$; the

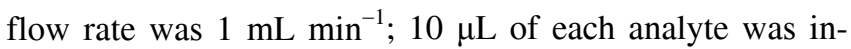
jected. The column temperature was maintained at $30^{\circ} \mathrm{C}$, DAD data were recorded from 200 to $800 \mathrm{~nm}$, and chromatograms of flavonoids were recorded at $256 \mathrm{~nm}$. Flavonoid peaks were identified by their retention time and coelution with pure compounds (rutin, quercetin-3- $\beta$-D-glucoside, and quercetin). The quantity of each compound was calculated from a regression analysis of peak areas against standard concentrations. All chemical analyses were conducted using three replicates.

\subsection{Inhibitory activity of rutin against $S$. costatum}

Rutin (Co. R5143, Sigma) was dissolved in methanol and then added to $\mathrm{f} / 2$ medium to obtain concentrations ranging from $2 \times 10^{-8}$ to $2 \times 10^{-5} \mathrm{~mol} \mathrm{~L} \mathrm{~L}^{-1}$. The controls were $\mathrm{f} / 2$ medium and a mixture of $\mathrm{f} / 2$ medium and methanol $(0.01 \%$, $\mathrm{v} / \mathrm{v})$. The $\mathrm{pH}$ and salinity of the culture medium were adjusted to $8.0 \pm 0.2$ and $30 \mathrm{psu}$, respectively. S. costatum cells in the exponential growth phase were inoculated into the aquaria to obtain an initial cell density of $1 \times 10^{3}$ cells $\mathrm{mL}^{-1}$. Each assay consisted of six replicates. All other conditions were the same as those described above. We prepared $S$. costatum cultures with five different initial algal densities: $0.01 \times 10^{3}, 0.1 \times 10^{3}, 1 \times 10^{3}, 10 \times 10^{3}$, and $100 \times 10^{3}$ cells $\mathrm{mL}^{-1}$, and then determined their growth responses to rutin. Each assay consisted of six replicates. All other experimental conditions were the same as those described above.

\subsection{Statistical analysis}

Data were analyzed with OriginPro 7.5 and SPSS 16.0 software packages. One-way analysis of variance (ANOVA) was used to test the significance of differences between treatments and the control. Subsequent multiple comparisons were performed with Tukey's test at $P \leqslant 0.05$ to compare the mean growth of S. costatum.

\section{Results}

\subsection{Growth inhibition of $S$. costatum by $S$. europaea in a co-culture system}

Time-course growth curves showed that growth of $S$. costatum was completely inhibited by $S$. europaea. Compared with the monoculture control, the algal cell density and Chl $a$ concentration in the presence of $S$. europaea was significantly reduced (Figure 1A and B). The inhibition ratio of $S$. costatum growth was time-dependent, and those of Chl $a$ concentration and cell density were $98.74 \%$ and $99.68 \%$ after $5 \mathrm{~d}$ of co-culture with $S$. europaea. The concentrations of DIN and DIP in the culture media were greater than 0.2 and $0.045 \mathrm{mg} \mathrm{L}^{-1}$, respectively, during the whole experiment (Figure 1C and D). Along with $S$. costatum growth, the DIP concentration in the control decreased to the lowest value at day 5 , and then increased as the bloom of $S$. costatum declined.

\subsection{Growth inhibition of $S$. costatum by $S$. europaea root extracts}

To further explore the inhibitory effect of $S$. europaea, we determined the effects of an aqueous and three organic (methanol, butanol, and chloroform) root extracts against $S$. costatum. We measured algal cell density, specific growth rate, and $\mathrm{IC}_{50}$. None of the solvents used in the extracts affected algal growth. When the alga was treated with the aqueous extract (Figure 2A), growth of S. costatum slightly increased at certain concentrations. However, all the organic extracts showed dose-dependent phytotoxic effects against growth of $S$. costatum, as indicated by the maximum cell density and specific growth rate (Figure 2B-D). Among the three organic extracts, the methanol extract most strongly inhibited algal growth. As shown in Table 1, the $\mathrm{IC}_{50}$ of the methanol extract was $4.05 \mathrm{mg} \mathrm{L}^{-1}$, followed by the butanol extract and the chloroform extract. Compared with algal cells in the control, those treated with any of the $S$. europaea extracts developed morphological abnormalities. All root extracts except the chloroform extract (Figure $2 \mathrm{H}$ ) induced larger $S$. costatum cell sizes in a dose-dependent manner. In addition, all extracts increased the Chl $a$ concentration in $S$. costatum cells in a dose-dependent manner.

Table $1 \mathrm{IC}_{50}{ }^{\mathrm{a})}$ of root extracts from $S$. europaea and rutin against $S$. costatum

\begin{tabular}{cccccc}
\hline & \multicolumn{4}{c}{ Root extracts $\left(\mathrm{mg} \mathrm{L}^{-1}\right)$} & \multirow{2}{*}{$\begin{array}{c}\text { Rutin } \\
\end{array}$} \\
\cline { 2 - 5 } & Water & Methanol & Butanol & Chloroform & $\left(\mathrm{mol} \mathrm{L}^{-1}\right)$ \\
\hline \multirow{2}{*}{$\mathrm{IC}_{50}$} & $\geqslant 4 \times 10^{3}$ & 4.05 & 5.26 & 11.3 & $6.69 \times 10^{-7}$ \\
& $( \pm 0.35)$ & $( \pm 0.11)$ & $( \pm 0.29)$ & $( \pm 1.18)$ & $( \pm 0.52)$ \\
\hline
\end{tabular}

a) $\mathrm{IC}_{50}$ was determined by plotting extract concentration against specific growth rate of $S$. costatum and calculating linear, sigmoid, exponential, and polynomial regression equations. The best-fitting model was chosen for each extract and rutin. Data are mean values $(n=6) \pm \mathrm{SE}$. 


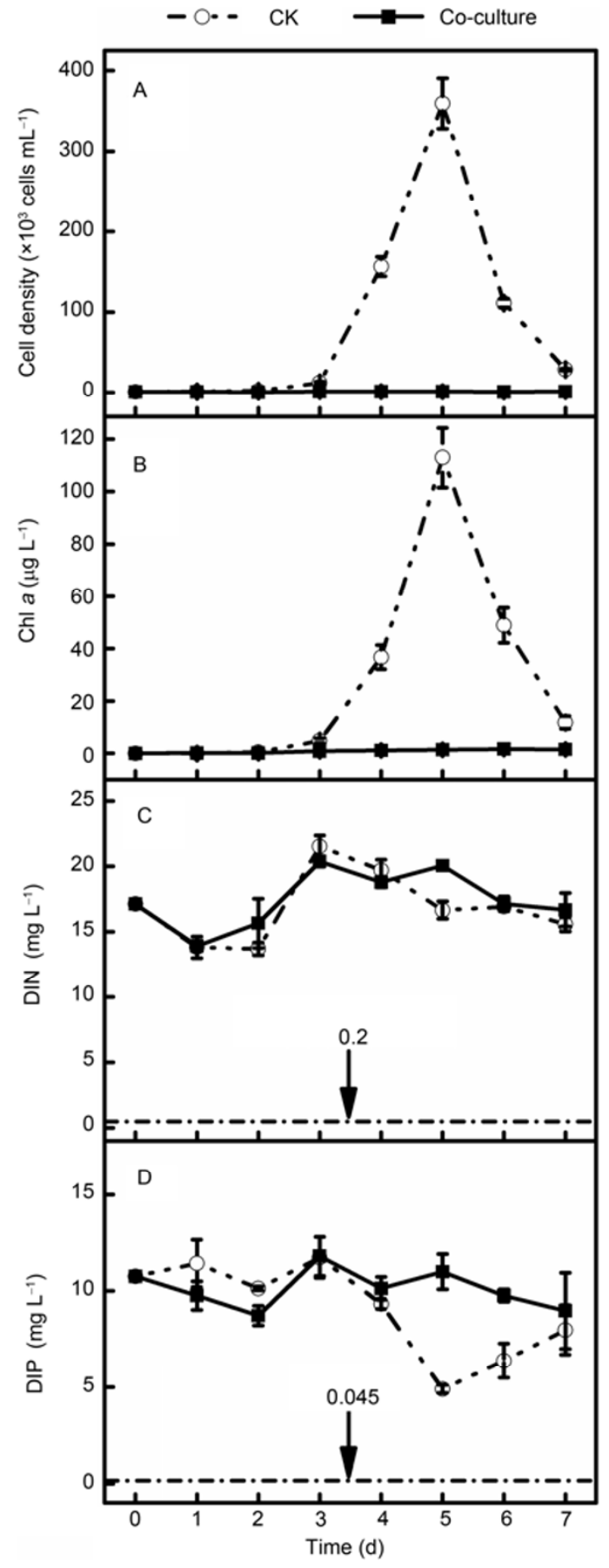

Figure 1 Inhibitory effects of $S$. europaea against growth of $S$. costatum: cell density (A) and chlorophyll $a$ concentration (Chl a) (B) in S. costatum; concentrations of dissolved inorganic nitrogen (DIN) (C) and dissolved inorganic phosphate (DIP) (D) in the culture medium. Monoculture of $S$. costatum served as the control. Dash-dot line indicates eutrophication threshold. Data are mean values $(n=6) \pm \mathrm{SE}$.

\subsection{Inhibitory activity of rutin towards growth of $S$. costatum}

Because $S$. costatum growth was much more sensitive to the methanol extract than to the other three extracts from $S$. europaea roots, we conducted an HPLC analysis to deter- mine the chemical composition of this extract. As shown in Figure 3, rutin and quercetin-3- $\beta$-D-glucoside were detected in the methanol extract. We plotted the peak area in the chromatogram against the concentration of rutin or quercetin-3- $\beta$-D-glucoside standard solutions to obtain a linear calibration curve for each substance (Figure 3C and D). The regression equation was $Y=0.00005 X-0.0004\left(R^{2}=1\right)$ for rutin and $Y=0.00004 X-0.0004\left(R^{2}=1\right)$ for quercetin-3- $\beta$ $D$-glucoside. The concentration of rutin in the root was $60.14 \mu \mathrm{g} \mathrm{g}^{-1}$, much higher than that of quercetin-3- $\beta$-Dglucoside $\left(29.48 \mu \mathrm{g} \mathrm{g}^{-1}\right)$.

To investigate the inhibitory effect of rutin against $S$. costatum, we carried out a dose-response curve experiment using a liquid culture assay. Results showed that the growth of the alga was not affected solely by the solvent. As shown in Figure 4A, algal growth was inhibited by rutin in a dose-dependent manner. The cell density and specific growth rate decreased with increasing concentrations of rutin. According to the regression analysis, the $\mathrm{IC}_{50}$ of rutin was $6.69 \times 10^{-7} \mathrm{~mol} \mathrm{~L}^{-1}$ (Table 1). The effect of rutin on $S$. costatum was also measured using algal cultures at different initial densities, to determine whether the inhibitory effect was attenuated with increasing algal density. The time-course growth curves showed that at lower initial algal densities $\left(\leqslant 1 \times 10^{3}\right.$ cells $\left.\mathrm{mL}^{-1}\right)$, rutin showed stronger inhibitory effects against algal growth (Figure 4B-F).

\section{Discussion}

The results of the co-culture experiment indicated that the growth inhibition of $S$. costatum was because of the phytotoxic activity of $S$. europaea, rather than nutrient competition. There have been some reports on the effects of marine macroalgae on growth of $S$. costatum, such as a negative effect of Laminaria japonica [17] and a positive effect of Laminaria digitata [18]. However, there have been few reports on the inhibitory effects of a marine alga against $S$. costatum in a co-culture system or field study. An and colleagues [17] also reported that crude extracts from the marine macroalga Porphyra tenera inhibited growth of S. costatum; nevertheless, the growth rate of the latter was higher in a co-culture system [19]. In another study, the culture filtrate of Ulva lactuca significantly inhibited S. costatum in the first 1 or 2 days, but algal growth increased slightly from day 3 [20]. These findings indicate that the effects of marine macroalgae on growth of species that cause HABs (e.g., S. costatum) can be inconsistent. In our study, unlike the multiple effects of marine macroalgae, the culture filtrate of S. europaea strongly suppressed growth of the alga (see Appendix in the electronic version), and consistently showed an inhibitory effect over time and at different concentrations. This result may partly explain the reduction of $S$. costatum cell density in the Yundang Lagoon after a year of 

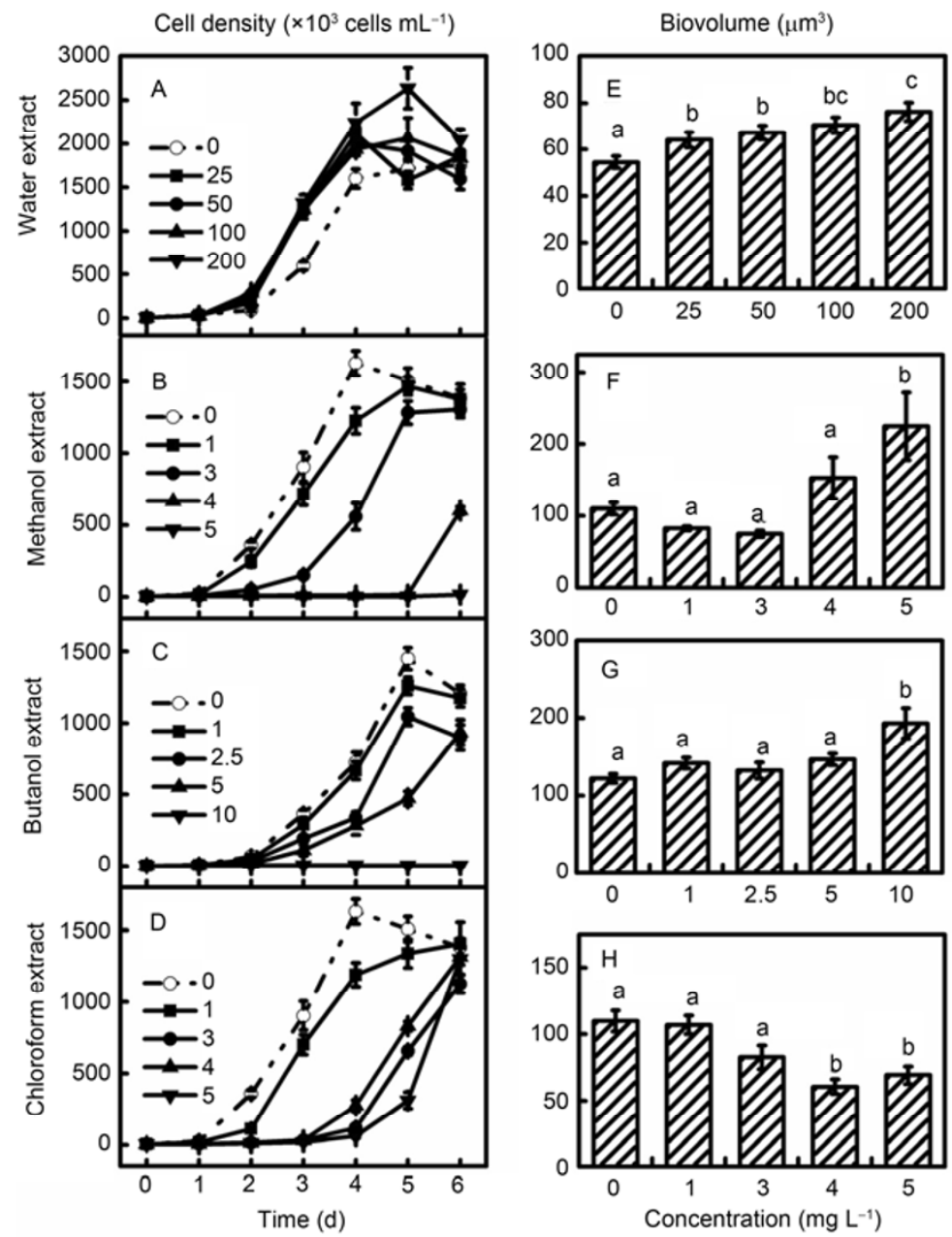

Chl a cell quota $\left(\times 10^{-12} \mathrm{~g} / \mathrm{cell}\right)$
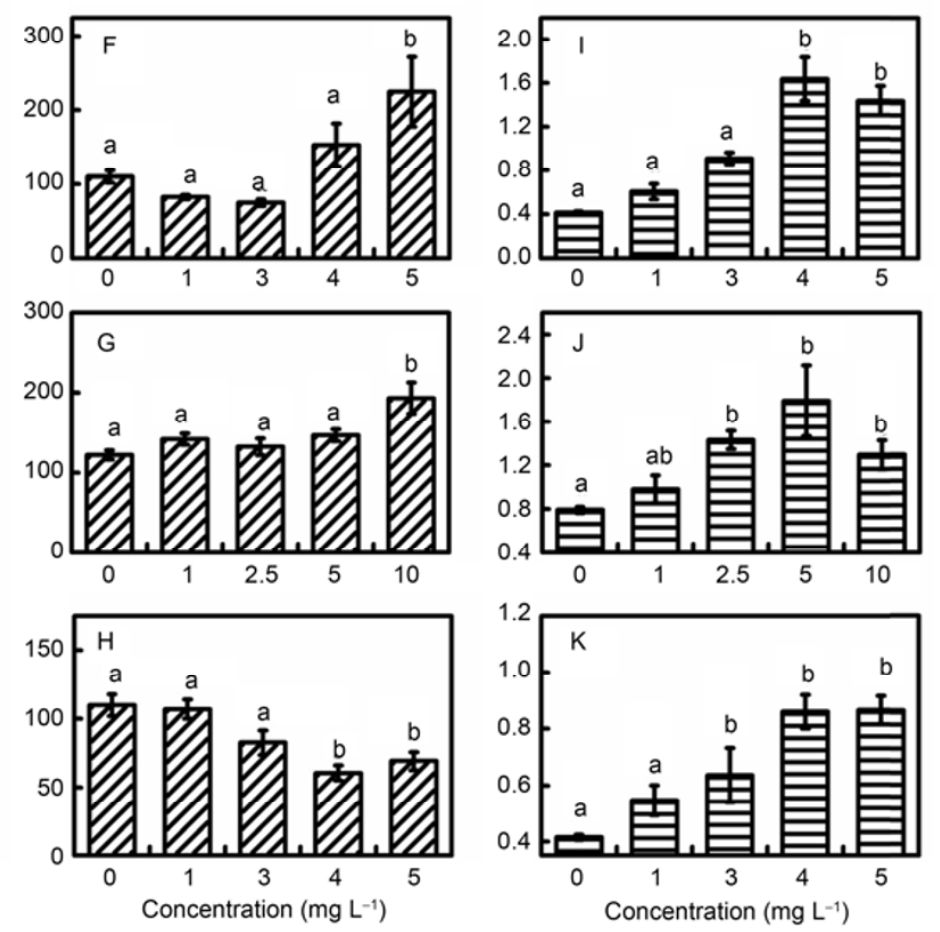

Figure 2 Growth of $S$. costatum in response to $S$. europaea root extracts: water (A and E), methanol (B, F, I), butanol (C, G, J), and chloroform (D, H, K). Monoculture of $S$. costatum served as the control. Cell density $\left(\times 10^{3}\right.$ cells $\left.\mathrm{mL}^{-1}\right)$, biovolume $\left(\mu \mathrm{m}^{3}\right)$, and chlorophyll $a$ concentration $\left(\times 10^{-12} \mathrm{~g} /\right.$ cell $)$ are shown plotted against different extract concentrations $\left(\mathrm{mg} \mathrm{L}^{-1}\right)$. Mixture of solvent and $\mathrm{f} / 2$ medium served as control. Data are mean values $(n=6$ for density and Chl $a ; n=50$ for cell size) \pm SE. Significant differences between treatments and control were tested using one-way ANOVA followed by Tukey's tests $(P \leqslant 0.05)$.

S. europaea cultivation in a floating phytoremediation platform system. However, the long-term ecological significance of S. europaea cultivation should be further investigated in field studies and in studies on the mechanisms underlying the different interactions between $S$. costatum and marine macroalgae or salt marsh plants.

In this study, bioassay tests with root extracts from $S$. europaea using different solvents showed that methanol extracts inhibited algal growth most effectively. This is consistent with the results of Erhard and Gross [21]. Wang et al. [22] reported that methanol extracts from Ulva linza, Corallina pilulifera, and Sargassum thunbergii strongly inhibited growth of Prorocentrum donghaiense. Hydroxy5a,6a-epoxy-7-megastigmen-9-one and 8-hydroxy-4E,6Eoctadien-3-one, identified in the seaweed Gracilaria lemaneiformis, are ethyl acetate-soluble compounds that moderately inhibited the growth of $S$. costatum [23]. In the present study, the organic extracts inhibited growth, whereas the aqueous extract showed a subtle stimulatory effect on growth of S. costatum. This was observed previously, and was reported as a fertilization effect at very low concentrations [24]. Alternatively, the extract may have had a chelating effect on some micronutrients in the culture medium [25].

Our results showed that the biovolume of $S$. costatum increased when it was exposed to methanol, butanol, and water extracts from $S$. europaea root (Figure 2E-H). These findings are consistent with those of Mulderij et al. [26], who reported that the cell size of Scenedesmus obliquus significantly increased in the presence of Stratiotes exudates. The authors considered that the increased cell size of $S$. obliquus would enhance the sedimentation rate, and thereby the disappearance rate, of this species from the water. In addition to negative effects on algal morphology, inhibitory compounds can also disrupt the physiological functions of algal cells, such as the photosynthetic system [27]. In our study, all organic extracts increased the Chl $a$ concentration in $S$. costatum cells in a dose-dependent manner. Hilt [28] 

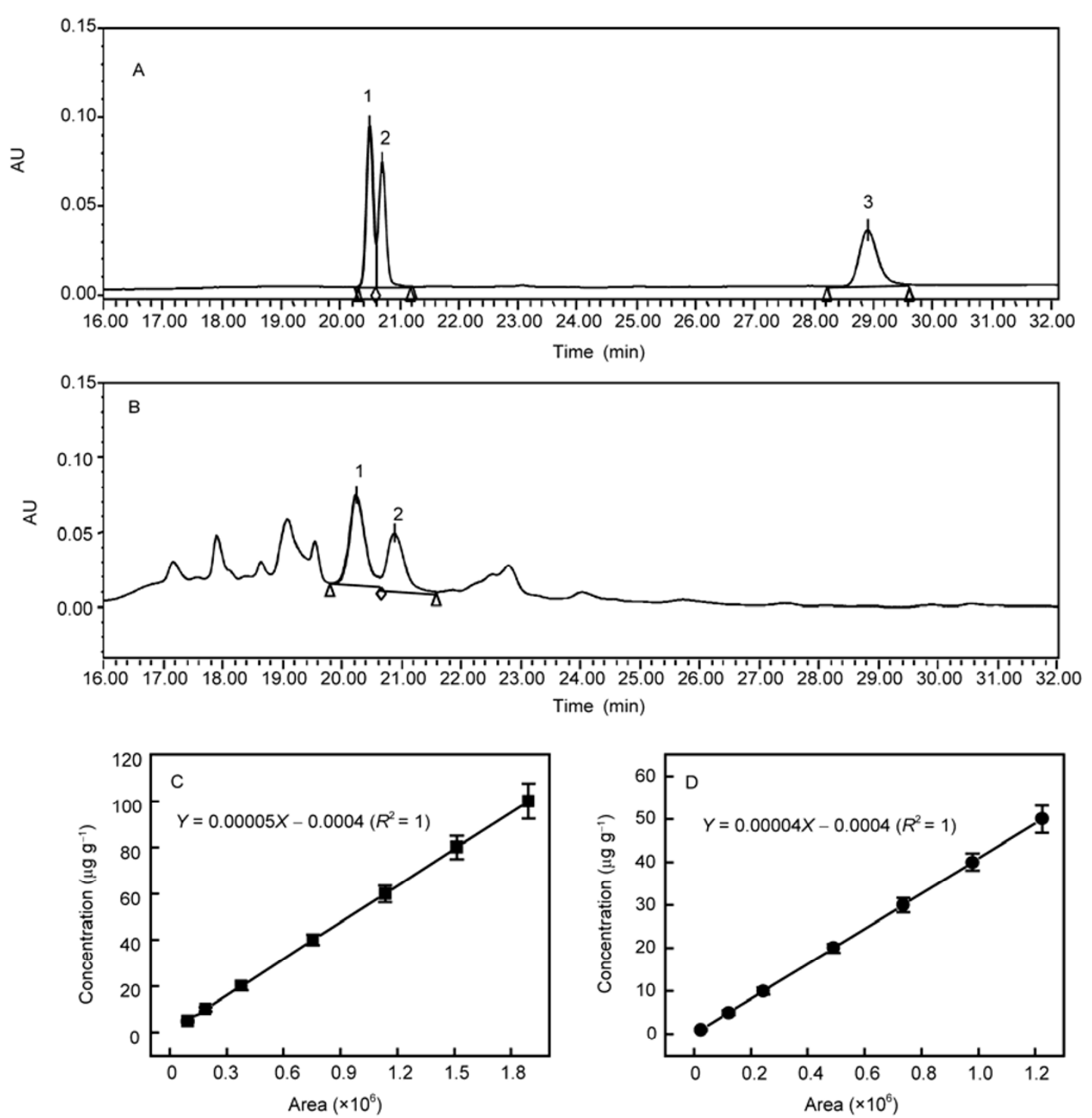

Figure 3 HPLC chromatograms of standard flavanoids (A) and methanol extract (B) of S. europaea root: peak 1, rutin; peak 2, quercetin-3- $\beta$-D- glucoside; peak 3, quercetin. Calibration curves for rutin (C) and quercetin-3- $\beta$-D-glucoside (D). Data are mean values $(n=3) \pm$ SE

also reported that the $\mathrm{Chl} a$ concentration and PSII activity of Scenedesmus armatus co-cultured with Myriophyllum spicatum were significantly higher than those of the controls. These observations could reflect a compensatory response or an evolutionary adaptation of the alga as a survival strategy, as discussed in a previous report [29].

HPLC analysis of the methanol extract of S. europaea root identified two flavonoids, rutin and quercetin-3- $\beta$-Dglucoside (Figure 3 ). Rutin has been shown to have antioxidant properties [30,31], and inhibitory effects against growth of crop plants [32], bacteria [33], and human glioblastoma cells [34]. Our study is the first report that rutin inhibits the growth of a marine diatom. We found that certain concentrations of rutin decreased the cell density of $S$. costatum and suppressed algal growth. Moreover, the inhibitory activity of rutin was negatively related to initial algal density, consistent with the effects of the algaecides N-phenyl-2-naphthylamine [35], eathyl-2-methyl acetoacetate [36], and gramine [37]. The $\mathrm{IC}_{50}$ of rutin against growth of $S$. costatum was $6.69 \times 10^{-7} \mathrm{~mol} \mathrm{~L}^{-1}$, which was much lower than its concentration in the root extract, suggesting that it may have been present at a significant concentration in the co-culture filtrate. However, we failed to determine the concentration of rutin in the culture filtrate. In future studies, we will determine the types and amounts of compounds that are released from S. europaea. Further studies should be conducted to analyze the biodegradation products, and to determine systematically the bioselectivity and biosafety of allelochemicals on aquatic biota. The results of such studies will guide the use of inhibitory plants or their products in practical applications.

In conclusion, our results show that $S$. europaea nega- 

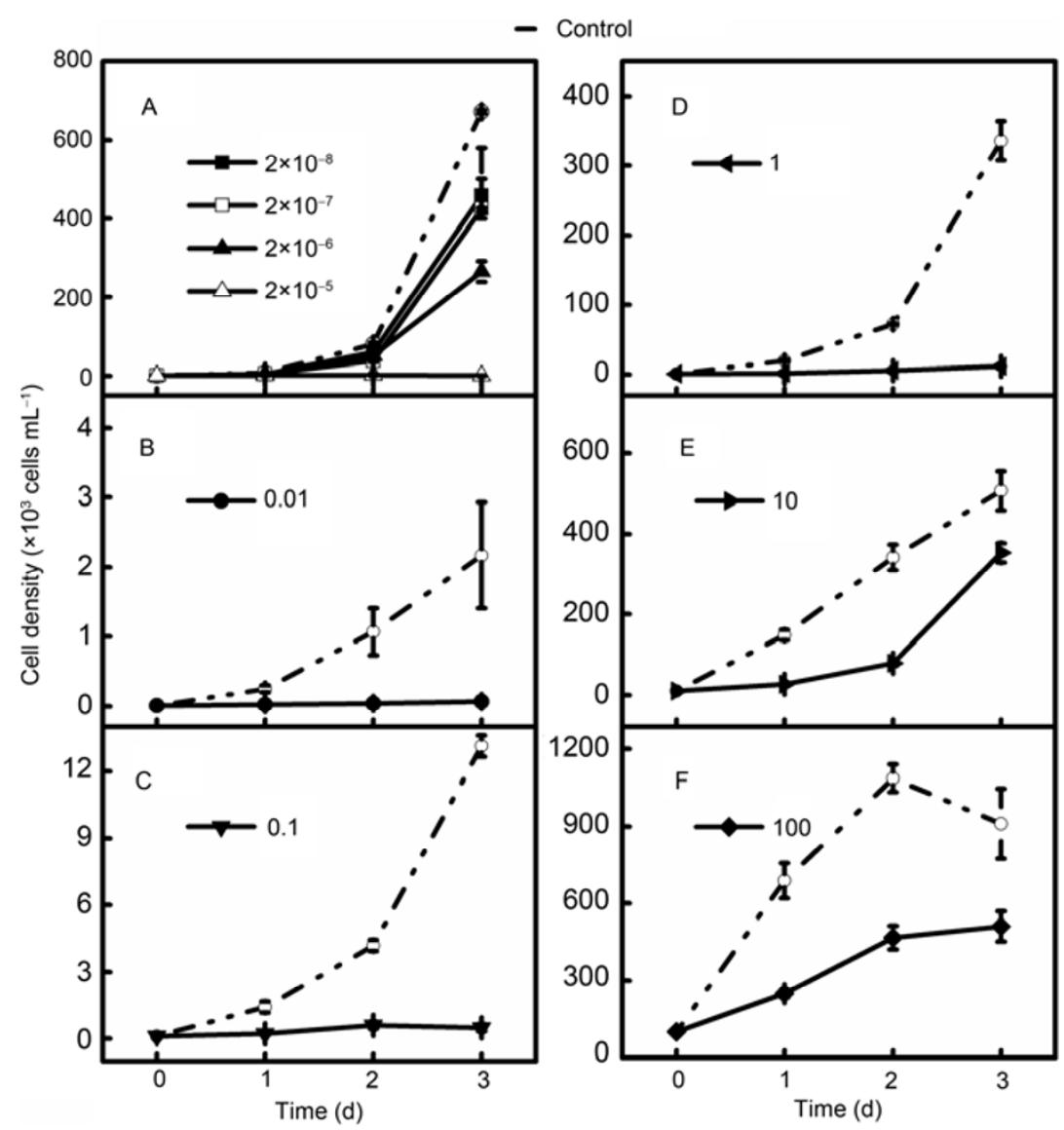

Figure 4 Growth inhibition of $S$. costatum by rutin: A, S. costatum with initial cell density of $1 \times 10^{3}$ cells $\mathrm{mL}^{-1}$ under different concentrations of rutin. B-F, Effects of rutin $\left(6.69 \times 10^{-7} \mathrm{~mol} \mathrm{~L}^{-1}\right)$ on $S$. costatum at different initial algal densities. Data are mean values $(n=6) \pm \mathrm{SE}$.

tively affected the growth of $S$. costatum in a co-culture system. Organic extracts from the $S$. europaea root inhibited growth of $S$. costatum, and affected the cell size of the alga and its chlorophyll $a$ content in a dose-dependent manner. Rutin, identified from $S$. europaea root extracts, may play an important role in inhibiting algal growth. It could be a promising algaecide to control $S$. costatum blooms.

This work was supported by the Knowledge Innovation Project of Chinese Academy of Sciences (Grant No. KSCX2-EW-J-1) and the National High Technology and Research Development Program of China (Grant No. 2007AA091704)

1 Geohab. Global Ecology and Oceanography of Harmful Algal Blooms, Science Plan. Baltimore and Paris: SCOR and IOC, 2001. 87

2 El-Sheekh M M, Khairy H M, El-Shenody R A. Allelopathic effects of cyanobacterium Microcystis aeruginosa Kutzing on the growth and photosynthetic pigments of some algal species. Allelopathy J, 2010, 26: 275-289

3 Kaya K, Sano T. Algicidal compounds in yeast extract as a component of microbial culture media. Phycologia, 1996, 35: 117-119

4 Legrand C, Rengefors K, Fistarol G O, et al. Allelopathy in phytoplankton-biochemical, ecological and evolutionary aspects. Phycologia, 2003, 42: 406-419

5 Zhang T, Wang L, He Z, et al. Growth inhibition and biochemical changes of cyanobacteria induced by emergent macrophyte Thalia dealbata roots. Biochem Syst Ecol, 2011, 39: 88-94

6 Hong Y, Hu H. Effects of the aquatic extracts of Arundo donax L. on the growth of freshwater algae. Allelopathy J, 2007, 20: 315-325

7 Lin H, Zhang Y, Chen J. Eutrophication assessment of seawater for Xiamen sea area. Taiwan Haixia, 2002, 21: 154-161

8 Xu C Y. Distribution of phytoplankton in Yundang Lagoon and ecological assessment (in Chinese). J Fujian Fisher, 2005: 16-21

9 Ozawa T, Miura M, Fukuda M, et al. Cadmium tolerance and accumulation in a halophyte Salicornia europaea as a new candidate for phytoremediation of saline soils. Osaka: Graduate School of Life and Environmental Sciences, Osaka Prefecture University 1881-6789. 2010. 1-8

10 Tikhomirova N, Ushakova S, Tikhomirov A, et al. Possibility of Salicornia europaea use for the human liquid wastes inclusion into BLSS intrasystem mass exchange. Acta Astronaut, 2008, 63: 11061110

11 Guillard R R, Ryther J H. Studies of marine planktonic diatoms. I. Cyclotella nana Hustedt, and Detonula confervacea (cleve) Gran. Can J Microbiol, 1962, 8: 229-239

12 Jiang D, Huang L, Lin S, et al. Allelopathic effects of euhalophyte Salicornia bigelovii on marine alga Skeletonema costatum. Allelopathy J, 2010, 25: 163-172

13 Eppley R W. Temperature and phytoplankton growth in the sea. Fish Bull, 1972, 70: 1063-1085

14 Faust M, Altenburger R, Backhaus T, et al. Predicting the joint algal toxicity of multi-component s-triazine mixtures at low-effect concentrations of individual toxicants. Aquat Toxicol, 2001, 56: 13-32

15 Sun J, Liu D. Geometric models for calculating cell biovolume and surface area for phytoplankton. J Plankton Res, 2003, 25: 1331-1346

16 Escarpa A, González M C. Fast separation of (poly) phenolic com- 
pounds from apples and pears by high-performance liquid chromatography with diode-array detection. J Chromatogr, 1999, 830: 301309

17 An Z, Wang Z, Li F, et al. Allelopathic inhibition on red tide microalgae Skeletonema costatum by five macroalgal extracts. Front Environ Sci Engin China, 2008, 2: 297-305

18 Pmkash A, Rashicl M A, Jensen A, et al. Influence of humic substances on the growth of marine phytoplankton: diatoms. Limnol Oceanogr, 1973, 18: 516-524

19 Sasaki K, Uno S. Comparison of the growth rate of six diatom species cultured with a red alga Porphyra tenera. Bull Plankton Soc Japan, 1988, 35: 57-65

20 Nan C, Zhang H, Lin S, et al. Allelopathic effects of Ulva lactuca on selected species of harmful bloom-forming microalgae in laboratory cultures. Aquat Bot, 2008, 89: 9-15

21 Erhard D, Gross E M. Allelopathic activity of Elodea canadensis and Elodea nuttallii against epiphytes and phytoplankton. Aquat Bot, 2006, 85: 203-211

22 Wang R, Xiao H, Wang Y, et al. Effects of three macroalgae, Ulva linza (Chlorophyta), Corallina pilulifera (Rhodophyta) and Sargassum thunbergii (Phaeophyta) on the growth of the red tide microalga Prorocentrum donghaiense under laboratory conditions. J Sea Res, 2007, 58: 189-197

23 Lu H, Xie H, Gong Y, et al. Secondary metabolites from the seaweed Gracilaria lemaneiformis and their allelopathic effects on Skeletonema costatum. Biochem Syst Ecol, 2011, 39: 397-400

24 Dayan F E, Duke S O. Clues in the search for new herbicides. In: Reigosa M J, Pedrol N, González L, eds. Allelopathy: A Physiological Process with Ecological Implications. Springer: Amsterdam, 2006. 63-68

25 Poulson K L, Sieg R D, Prince E K, et al. Allelopathic compounds of a red tide dinoflagellate have species-specific and context-dependent impacts on phytoplankton. Mar Ecol-Prog Ser, 2010, 416: 69-78

26 Mulderij G, Mooij W M, Donk E V. Allelopathic growth inhibition and colony formation of the green alga Scenedesmus obliquus by the aquatic macrophyte Stratiotes aloides. Aquat Ecol, 2005, 39: 1121

27 Gross E M. Allelopathy of aquatic autotrophs. Crit Rev Plant Sci, 2003, 22: 313-339

28 Hilt S. Allelopathic inhibition of epiphytes by submerged macrophytes. Aquat Bot, 2006, 85: 252-256

29 Körner S, Nicklisch A. Allelopathic growth inhibition of selected phytoplankton species by submerged macrophytes. J Phycol, 2002, 38: 862-871

30 La Casa C, Villegas I, Alarcón de la Lastra C, et al. Evidence for protective and antioxidant properties of rutin, a natural flavone, against ethanol induced gastric lesions. J Ethnopharmacol, 2000, 71: 45-53

31 Yang J, Guo J, Yuan J. In vitro antioxidant properties of rutin. LWT -Food Sci Technol, 2008, 41: 1060-1066

32 Kazinczi G, Onofri A, Szabo L, et al. Phytotoxic effects of Convolvulus arvensis weed on crops. Allelopathy J, 2007, 20: 179-193

33 Basile A, Sorbo S, Giordano S, et al. Antibacterial and allelopathic activity of extract from Castanea sativa leaves. Fitoterapia, 2000, 71: S110-S116

34 Santos B, Silva A, Pitanga B, et al. Antiproliferative, proapoptotic and morphogenic effects of the flavonoid rutin on human glioblastoma cells. Food Chem, 2011, 127: 404-411

35 Qian H, Xu X, Chen W, et al. Allelochemical stress causes oxidative damage and inhibition of photosynthesis in Chlorella vulgaris. Chemosphere, 2009, 75: 368-375

36 Hong Y, Hu Y, Li F. Growth and physiological responses of freshwater green alga Selenastrum capricornutum to allelochemical ethyl 2-methyl acetoacetate (EMA) under different initial algal densities. Pestic Biochem Physiol, 2008, 90: 203-212

37 Hong Y, Hu H Y, Xie X, et al. Gramine-induced growth inhibition, oxidative damage and antioxidant responses in freshwater cyanobacterium Microcystis aeruginosa. Aquat Toxicol, 2009, 91: 262-269

Open Access This article is distributed under the terms of the Creative Commons Attribution License which permits any use, distribution, and reproduction in any medium, provided the original author(s) and source are credited. 